I d u c a c i , o n

\title{
Proyecto Educativo Institucional
}

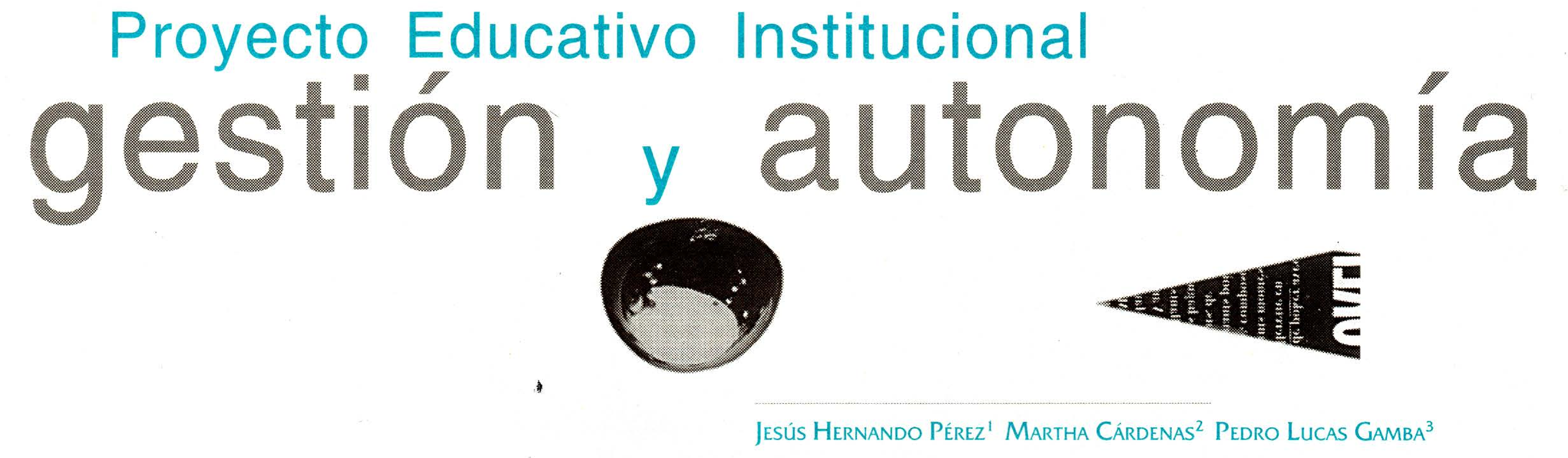

6

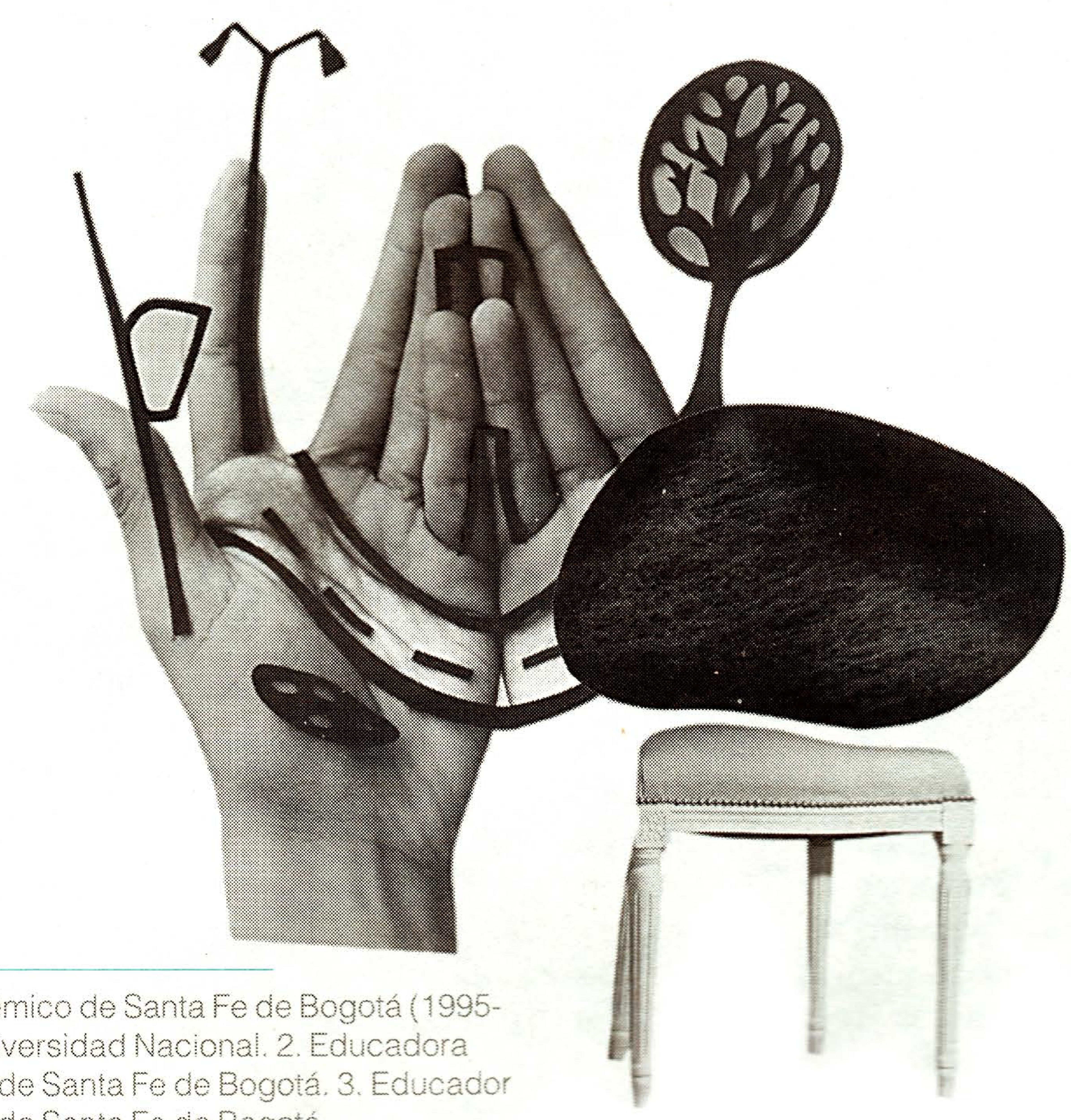

1. Exsubsecretario académico de Santa Fe de Bogotá (19951997 y prolesor de la Universidad Nacional. 2. Educadora Secretarla de Educación de Santa Fe de Bogotá. 3. Educador Secretariade Educacion de Santa Fe de Bogotá. 


\section{en Santafé de Bogotá}

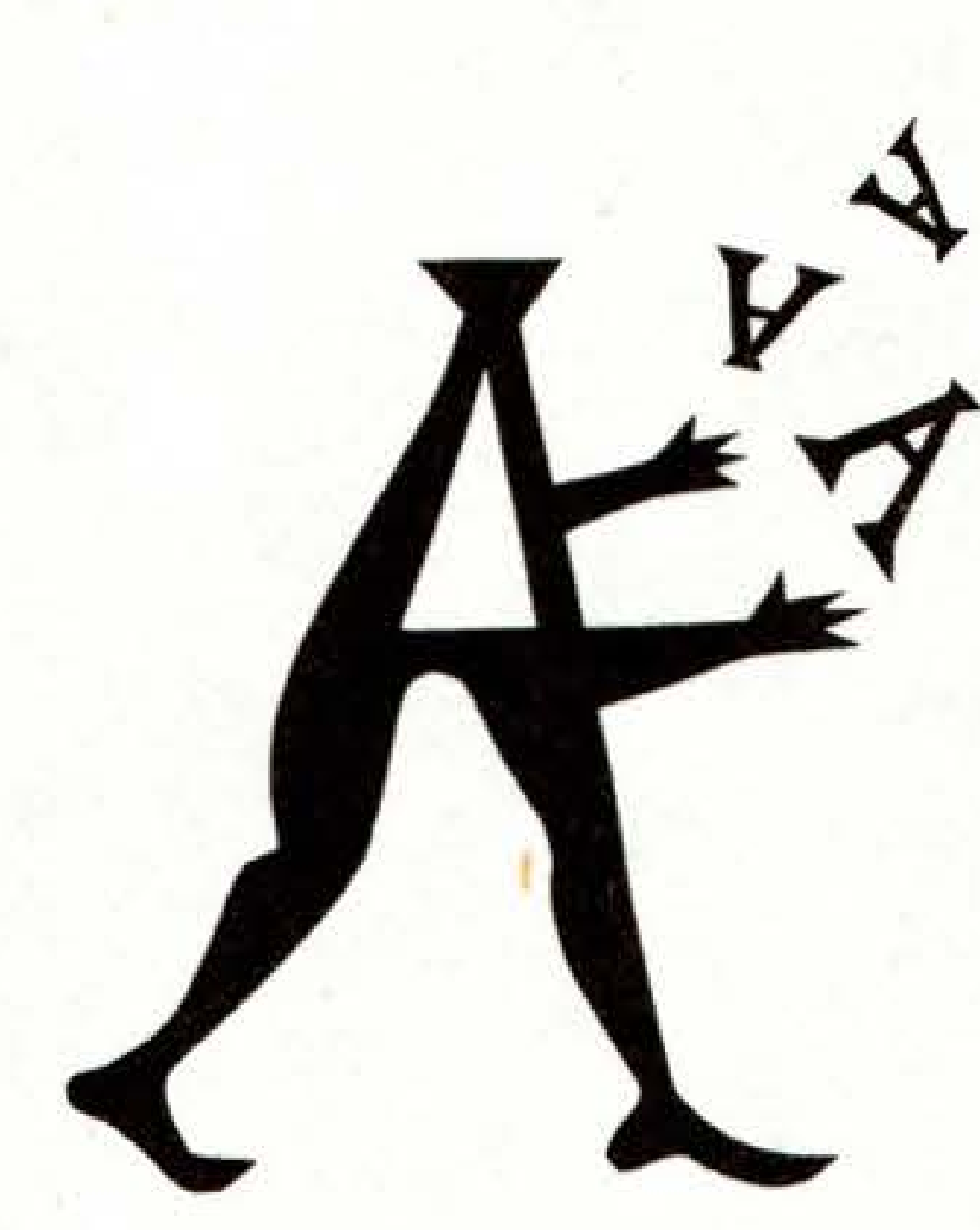

formarse y modernizarse. Los procesos de globalización y descentralización, el desarrollo acelerado de la ciencia y la tecnología, la creciente importancia del conocimiento, la mayor participación ciudadana que exige nuevas formas de relación y servicios más eficientes, y la gran movilidad del mundo del trabajo, demandan al nuevo ciudadano el desarrollo de potencialidades cuyas bases se deben formar en la institución escolar. Ella no puede seguir preparando personas para una época que el mundo contemporáneo dejó atrás.

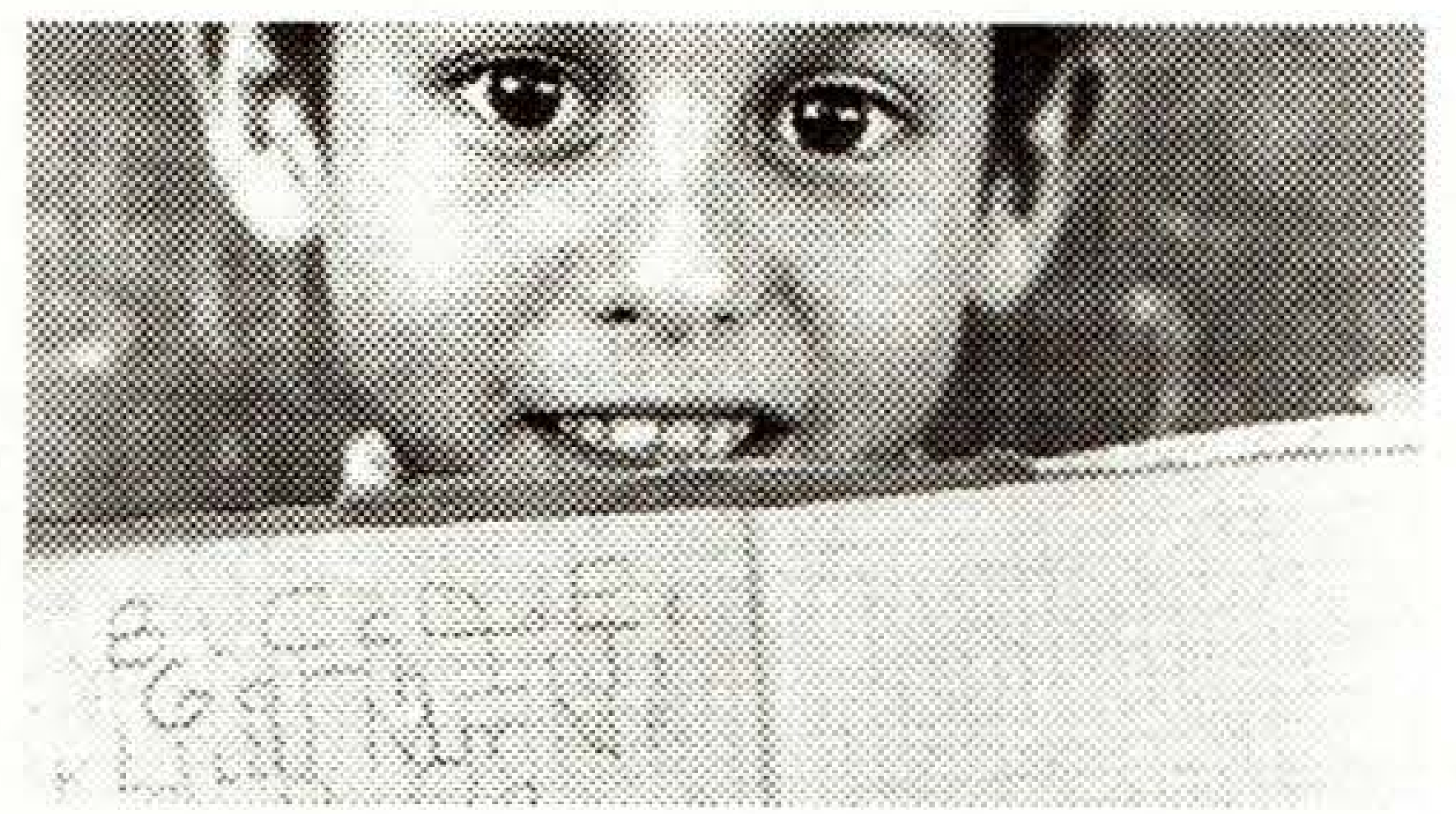

Las instituciones escolares cuentan con herramientas muy poderosas para transformarse, especialmente las consagradas en la Ley General de Educación, en particular, el Proyecto Educativo Institucional. Este ha planteado nuevos retos, entre ellos, la creación de un gobierno escolar, en el cual la participación efectiva de los padres y madres de familia, los educadores, los estudiantes y el sector productivo, introduce nuevas realidades que la enriquecen en forma sustancial.
La nueva situación requiere otras reglas de juego y un tipo de gestión completamente diferente, fundamentado en la participación. Se participa no por el mero prurito de partici- par; se hace porque se tienen nuevas ideas, nuevas propuestas, nuevas exigencias. Administrar una institución escolar dispuesta a cambiar y decidida a hacerlo con la presencia efectiva de la comunidad educativa, exige transformaciones profundas en la gestión escolar. La institución escolar se transforma no sólo porque el mundo cambia, lo hace también porque hay formas novedosas de gestión. La descentralización, por ejemplo, conduce, tarde 


$\begin{array}{lllllllllll}\mathrm{e} & \mathrm{d} & \mathrm{u} & \mathrm{c} & \mathrm{a} & \mathrm{c} & \mathrm{i} & \text { ó } & \mathrm{n}\end{array}$

que temprano, a que la institución oficial maneje directamente sus propios recursos y de manera autónoma; hay que prepararse para esto. Por esos motivos, el Proyecto Educativo Institucional debe entenderse como un instrumento que facilita el desarrollo de otras modalidades de gestión escolar.

Hoy más que nunca, se requiere mirar la institución escolar como una organización, que aprende y se transforma permanentemente. $\mathrm{Y}$ no hay que tenerle miedo a las propuestas del mundo académico y empresarial, que han dedicado su vida a investigar cómo funcionan las organizaciones, a entender el porqué algunas de ellas tienen mucho éxito mientras que otras fracasan en su gestión. Abrir la institución escolar significa también abrirla a este mundo académico en desarrollo: el de la gestión en general.
La Secretaría de - Educación de Santa Fe de Bogotá y sus instituciones escolares han venido tomando conciencia del importante papel de la gestión escolar y por ello han emprendido acciones tendientes a conocer propuestas y experiencias, a formarse y a emprender procesos de experimentación e investigación en este campo.

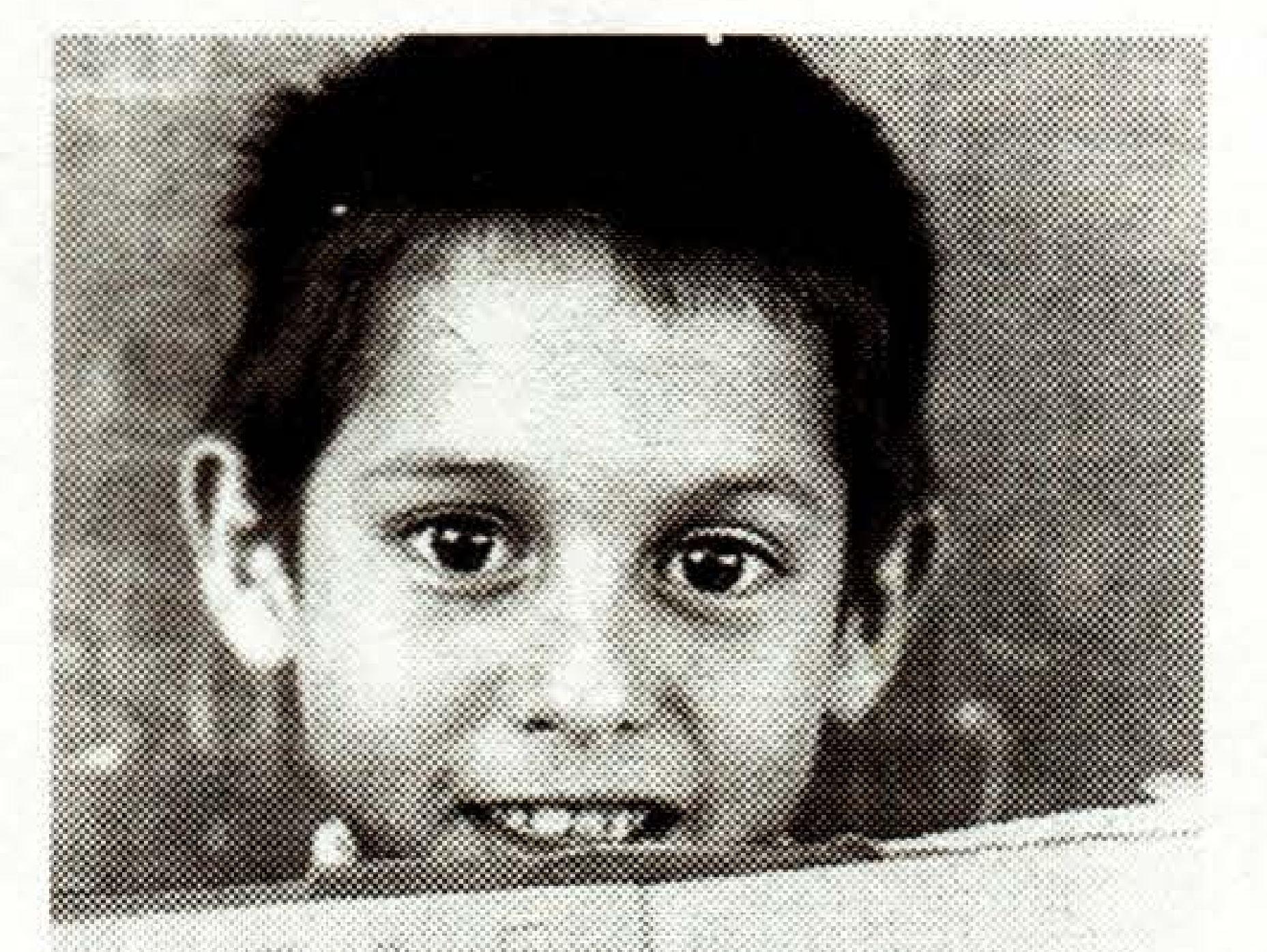

Otros países también vienen desarrollando experiencias en gestión escolar con éxito notable. El Estado de Minas Gerais en Brasil, por ejemplo, desde hace seis años, implementa la metodología de la Gerencia de la Calidad Total (GCT) en educación. Se han apropiado de la teoría conocida mundialmente como GCT y la han adaptada al mundo de la educación, construyendo una nueva, cuyo nombre es la Gerencia de la Calidad Total en Educación (GTCE). Ella se ha venido desarrollando creativamente, tanto en su Secretaría de Educación como en las instituciones escolares; los resultados han sido realmente notables: de 5.000 instituciones existentes en el Estado, 1.000 han mejorado su organización y funcionamiento, tanto en lo administrativo como en lo académico. 
Con la visita del Grupo Pitágoras a Santa Fe de Bogotá, invitado por la Secretaría de Educación Distrital, en octubre de 1997, varios directivos docentes y numerosos educadores conocieron la experiencia de Minas Gerais y decidieron aprender de ella. Para apoyar este proceso se conformó la Red Distrital de la Calidad en Educación, la cual viene funcionando desde noviembre de 1997.

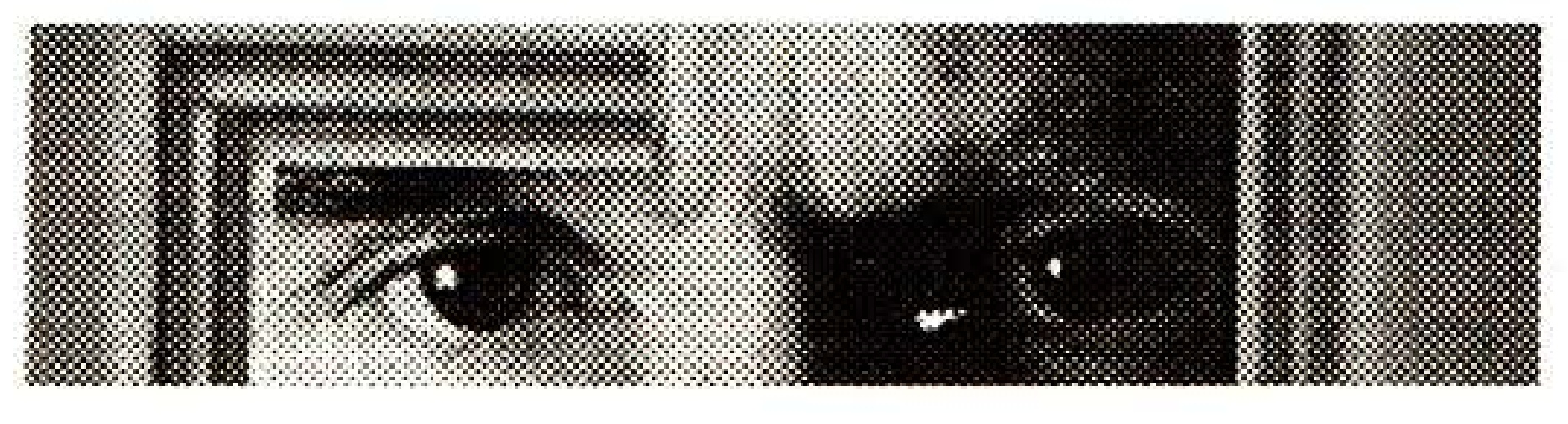

Las diversas experiencias nos muestran que la gestión escolar es un tema académico en la cual hay teorías, grupos académicos e investigadores, $\mathrm{pu}$ blicaciones, experimentos y resultados de gestión. Es un ámbito académico en el cual el directivo docente puede investigar al lado de sus profesores, estudiantes e incluso padres, madres de familia y empresarios. He aquí otra idea espectacular: al empresario también le interesa el tema de la gestión; él, a su manera, también es un académico en el tema de la gestión, es uno de nuestros pares. ¿No será ésta la forma adecuada de acercarse a las empresas y a los empresarios? Las instituciones escolares son también empresas, obviamente de tipo especial: son empresas culturales.
Y, ahora, la pregunta central: ¿cómo son los funcionarios de las empresas exitosas? En términos generales, son personas profesionales, identificadas completamente con su trabajo y dispuestas a gerenciar no sólamente el funcionamiento de la empresa, sino además cada una de sus actividades: los programas y los proyectos en los cuales participan, el funcionamiento de las dependencias a las cuales pertenecen, entre otras cosas.

¿No vale la pena, desde la escuela, cultivar esta cultura? Por supuesto que sí. Así lo han venido comprendiendo todas aquellas instituciones escolares que se proyectan como organizaciones que aprenden. Para apoyarlas, la Secretaría de Educación también inició un proceso para vincular más orgánicamente la escuela y la empresa, estableciendo "matrimonios" que buscan un aprendizaje mutuo, tanto en lo referente a la gestión como a la preocupación por la construcción de ciudad y de país. 
Los Proyectos Educativos

INSTITUCIONALES Y LA

CONSTRUCCIÓN DE LA AUTONOMÍA

Le correspondió a la Secretaría de Educación (1995-1997) " suscitar diversas acciones en aras a abrir el camino hacia el fortalecimiento de las instituciones escolares con su herramienta esencial, el Proyecto Educativo Institucional, y contribuir al mejoramiento de los procesos educativos en el Distrito Capital.
El Proyecto Educativo Institucional como proyecto cultural busca insertar la escuela en un proyecto de ciudad y de país, bajo condiciones de autonomía que antes no se habían tenido. Si bien consideramos que ésta es relativa, en tanto las funciones administrativas y financieras son limitadas, la autonomía intelectual y moral requiere ser construida desde el interior de las instituciones, y esto se logra a través de la participación de estudiantes, educadores, directivos docentes, padres y madres de familia.

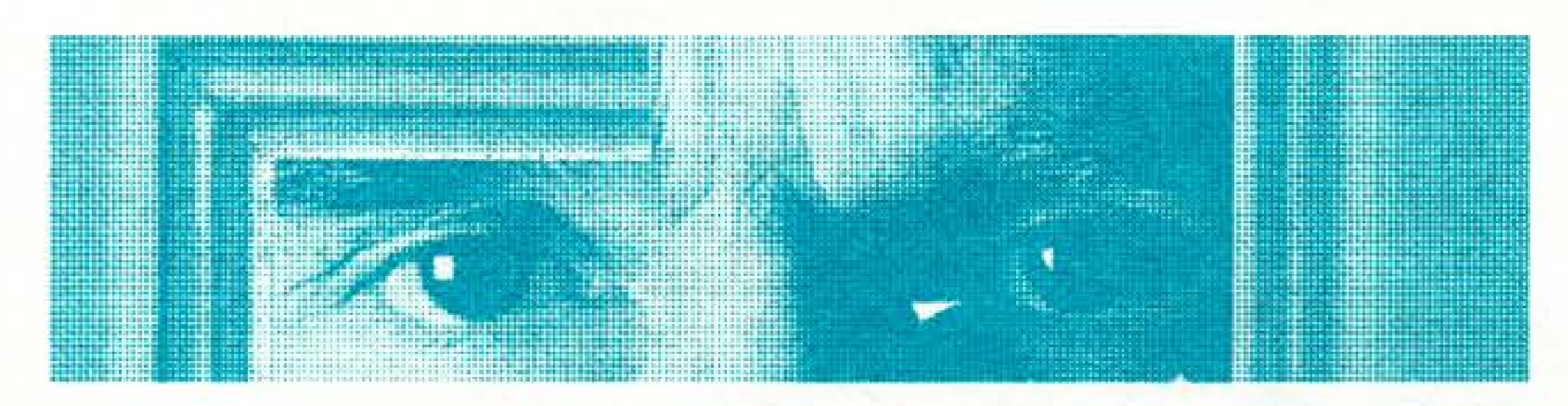

La autonomía la entendemos, entonces, como la capacidad y responsabilidad de la institución escolar de construir su propio proyecto educativo, con una gestión que le permita trazar su horizonte a mediano y largo plazo, dentro de los fines de la educación de nuestro país, fijar metas académicas y de convivencia y evaluar sus resultados. La autonomía lograda por la práctica de muchas instituciones del Distrito Capital manifiesta el compromiso adquirido por ellas y permite reconocer la diversidad existente, cada una con una experiencia y desarrollo de acuerdo a sus propias condiciones y a su entorno. 
Hacer un balance nos permite ver que la autonomía que se ha ido ganando se refleja en diversos aspectos:

- Fortalecimiento de los Gobierno Escolares, en particular los Comités Directivos. Ellos han venido promoviendo el ejercicio de la democracia, un aprendizaje difícil y valioso, que exige aprender a convivir todos los integrantes de la comunidad educativa: educadores, educadoras, directivos docentes, estudiantes, padres y madres de familia; respetándose $\mathrm{y}$ reconociéndose mutuamente en la diferencia. Optar porque la comunidad educativa participe en las decisiones que antes eran de la sola competencia de los directivos docentes, implica un cambio en la mentalidad, en la actitud y en la práctica de todos los estamentos; y ésto se viene ganando en buena parte de las instituciones, así en algunas sea aún muy precario.
Corresponde a los Comités Directivos, igualmente, la elaboración de su Proyecto Educativo Institucional. Algunos de ellos producto de una amplia discusión con los diferentes estamentos de la comunidad, determinando énfasis diversos, como se expresa en el registro presentado a la Secretaría de Educación: tecnología e informática, ciencias, medio ambiente, educación sexual, formación en valores y democracia, entre otros.

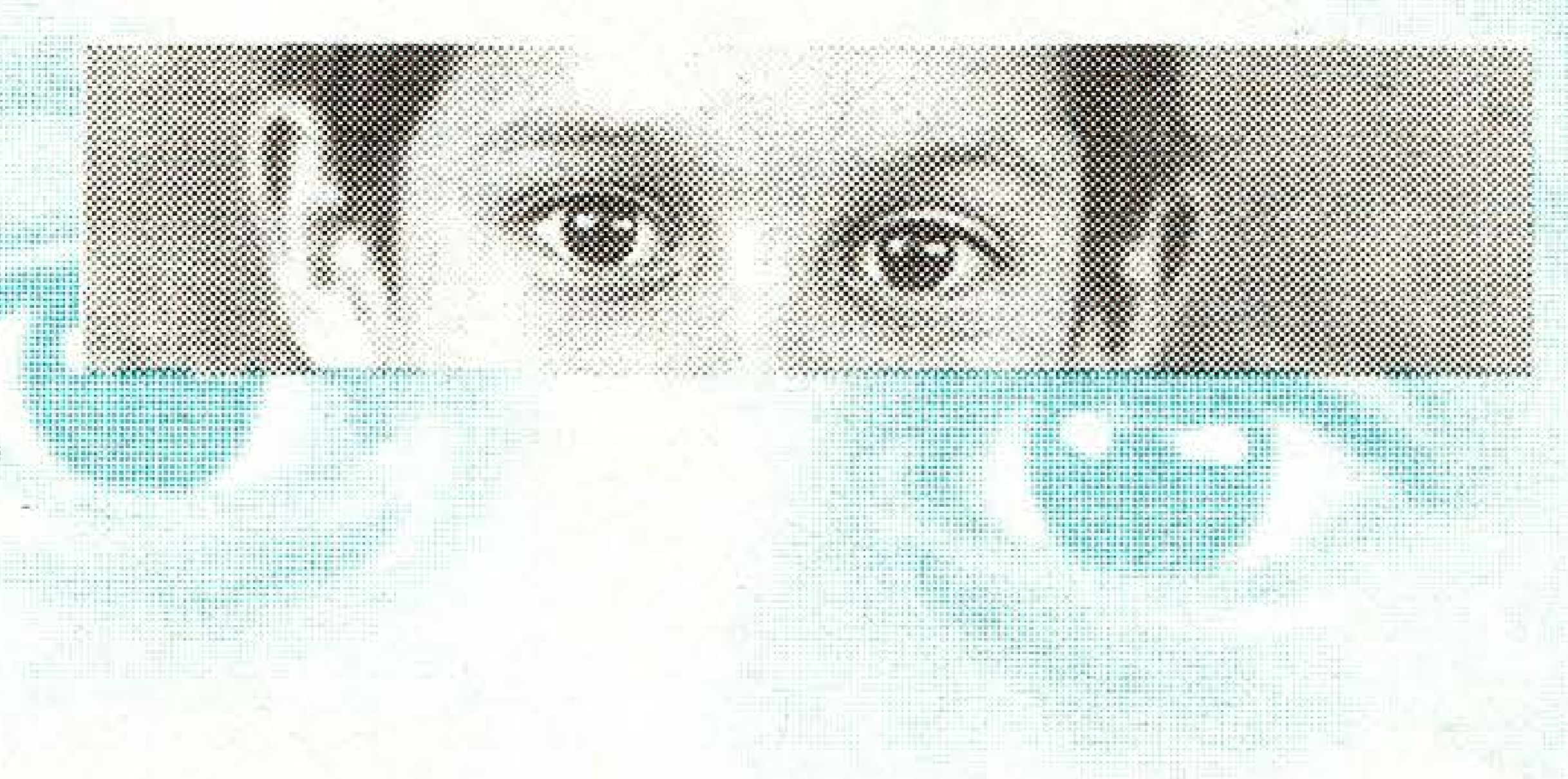

- Impulso a los Comités Académicos, los cuales tienen la responsabilidad de las propuestas de transformación del currículo de la institución. Sabemos que ésta es una labor de gran envergadura y, de ahí, que es aún muy incipiente en la mayoría de las instituciones escolares. El currículo, como concreción de los fines culturales y sociales de un país, requiere abrirse a nuevas propuestas que recojan los avances del conocimiento científico, - tecnológico, ético, estético y pedagógico. Surgen múltiples preguntas: ¿cómo acercar estos conocimientos a la escuela?, ¿cómo generar una ruptura con la tradicional asignatura?, ¿cómo construir proyectos pedagógicos que integren diversas áreas del conocimiento? 


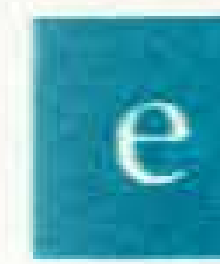

d

u

C

a

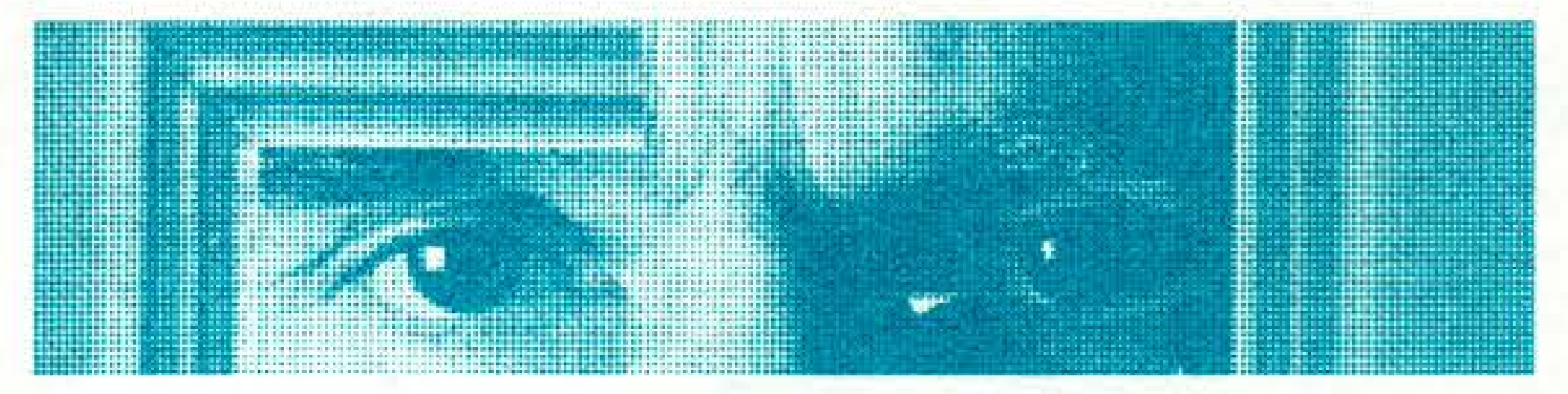

La Secretaría de Educael país. Este trabajo que ha ción crea el Comité Académico, bajo la dirección de la Subsecretaría Académica, como posibilidad de promover comunidad académica al interior de las instituciones de educación básica y media y en el cual los comités académicos vienen asumiendo la responsabilidad de promover el debate y la investigación. Como herramienta se edita la revista Sed Académica, con temas que aportan a las necesidades teóricas de los educadores.

- Fortalecimiento de las personerías estudiantiles. Son muchos los y las jóvenes de las instituciones escolares, estatales y privadas, que han venido en un proceso de formación para la participación y defensa de los derechos de los y las estudiantes. Fruto de ello es la Red Distrital de Líderes Juveniles que con autonomía y decisión se abren camino en las instituciones, en la ciudad y en contado con el apoyo de la Secretaría de Educación, exige también un soporte y garantías de los directivos docentes y maestros para el ejercicio de sus funciones y su corisolidación.

- Organización de las Asociaciones de Padres y Madres de Familia. Lo que legitima una institución escolar es la fortaleza de las diversas organizaciones que componen su comunidad, de ahí el interés de la Secretaría de Educación en consolidar procesos de organización de los padres y madres de familia que han logrado una mayor y mejor participación en los Gobiernos Escolares.

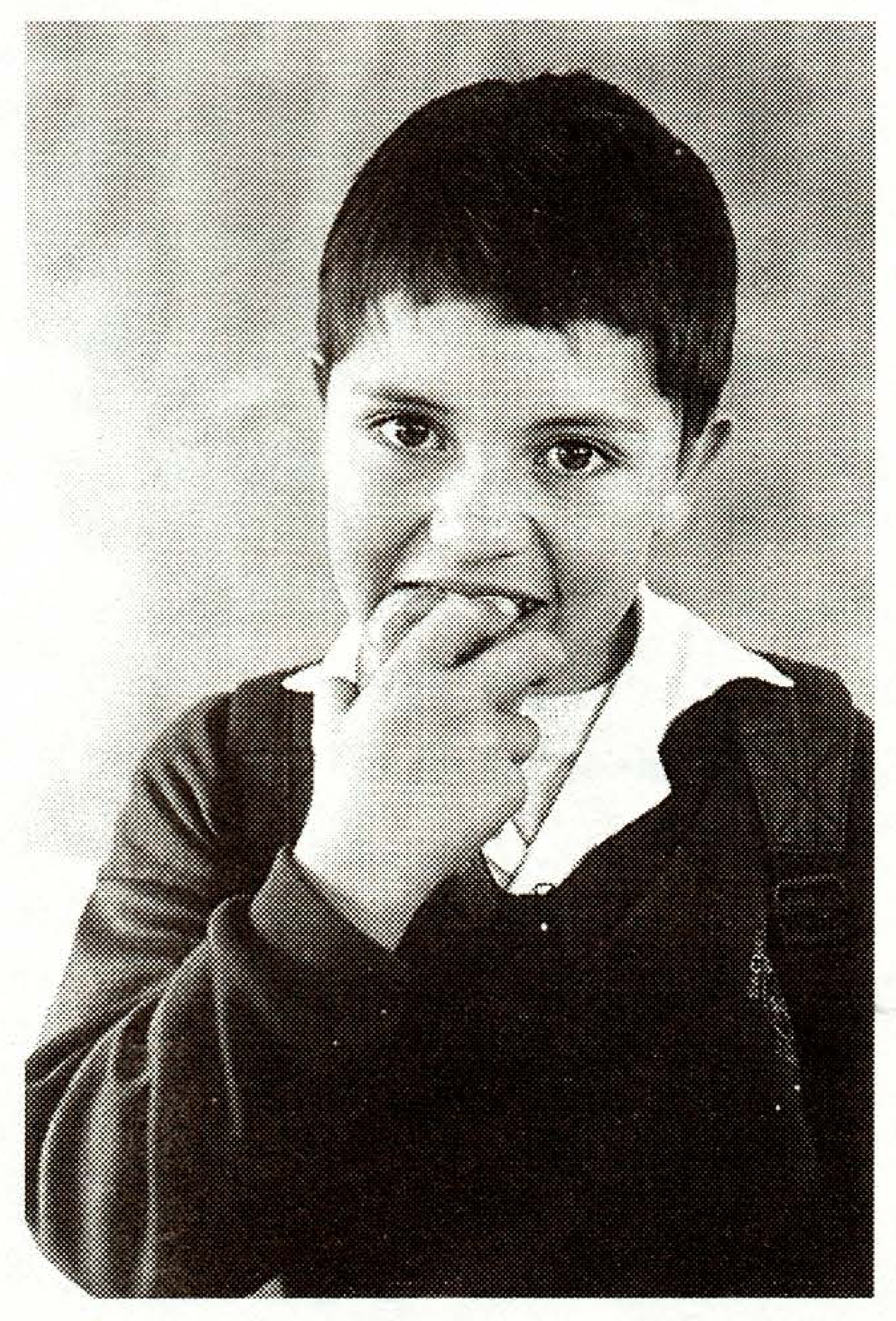




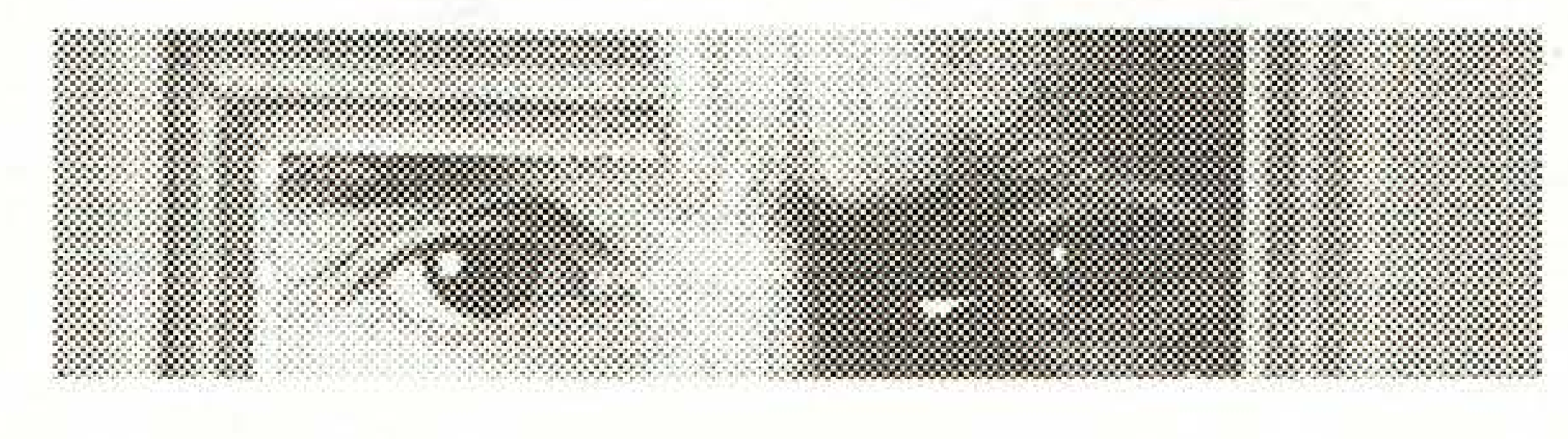

- Elaboración de proyectos pedagógicos que fortalecen el desarrollo de los Proyectos Educativos Institucionales y que cuentan con recursos económicos de la Secretaría de Educación. Algunos de ellos como propuestas de toda la institución pero también de grupos de maestros que vienen trabajando proyectos particulares en lenguaje, matemáticas, democracia, estética, tecnología, medio ambiente, juego y recreación, entre otros. El ejercicio de la autonomía ha llevado a que muchas instituciones y educadores elaboren y presenten proyectos de financiación para sus propuestas, tanto de investigación como de formación y de asesoría pedagógica, no sólo a la Secretaría de Educación, sino también a las Juntas Administradoras Locales (JAL), al IDEP, a Colciencias y a otras organizaciones gubernamentales y no gubernamentales.
- Una nueva dimensión de la formación de los educadores que supera la tradicional "feria del crédito" para asumirse como formación de los diversos estamentos para la construcción del Proyecto Educativo Institucional o para el desarrollo de proyectos pedagógicos particulares. La comprensión de estos procesos ha implicado dificultades, pero se ha ganado tanto en las ofertas por parte de las instituciones de educación superior que brindan los programas de formación como en los educadores que la reciben. Además, diversas escuelas y colegios vienen apoyándose en sus propios educadores, muchos de ellos con estudios universitarios avanzados, así como también educadores o grupos de investigación y estudio que hoy se promueven desde las diferentes localidades. Todas estas alternativas, mediante el ejercicio de la docencia y la investigación, intentan mejorar la calidad de la educación y contribuir a la transformación escolar.
El ejercicio de la autonomía y, por ende, la construcción de una comunidad académica al interior de las instituciones escolares, es un camino largo de recorrer y todas las instituciones lo asumen de diferentes maneras y ritmos, de acuerdo a sus propias experiencias y a las de los educadores y educadoras. Los aspectos señalados anteriormente, como manifestación de esa autonomía que se empieza a ganar, son aún incipientes, pero hay una confian- za plena en que cuando se han prendido motores ya no hay quien pare este proceso. 


\section{e \\ d \\ u \\ C \\ a \\ C \\ i \\ ó \\ Proyecto Educatin \\ Institucional autonomía}

\section{LOS PROYECTOS PEDAGÓGICOS}

En tanto la Secretaría de Educación busca que las instituciones escolares entren en un proceso de descentralización que conlleva la gestión de recursos financieros, el papel que debe cumplir es orientar el proceso de elaboración de propuestas que fortalezcan la construcción de proyectos pedagógicos e institucionales. Esto también implica un proceso de aprendizaje para la administración central, que en este período impulsa la propuesta de proyectos.

En este contexto, la Subsecretaría Académica, en 1997, abre una convocatoria para promover la formulación de proyectos pedagógicos y de gestión en las instituciones educativas.
Los Comités de Calidad y Cobertura de cada localidad de la ciudad son los encargados de efectuar la selección de estos proyectos de acuerdo a unos críterios mínimos establecidos, entre los cuales han tenido gran peso las actividades de carácter pedagógico y el número de estudiantes que participan en ellas. Toda la intencionalidad está encaminada a integrar con una participación activa a los estudiantes en los procesos académicos.

Otro propósito, no menos importante, está encaminado a fortalecer en el mediano plazo los Consejos Directivo y Académico de cada plantel, al colocar bajo su responsabilidad la formulación y seguimiento de los proyectos o en el menor de los casos dar su aval.

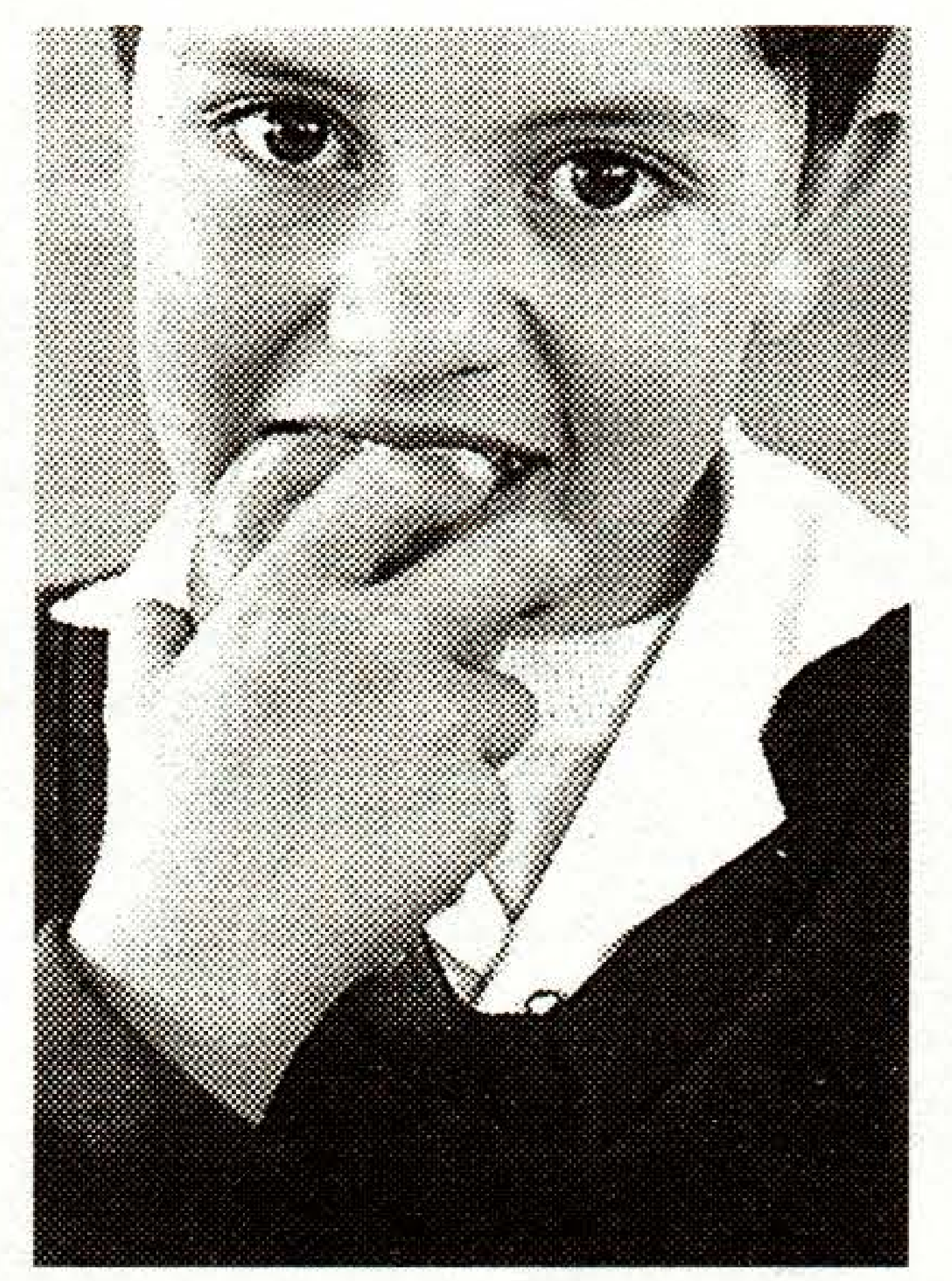

Los proyectos seleccionados por los comités locales son revisados por un grupo conformado por los Coordinadores del Cuerpo Técnico de Supervisión y de CADEL de cada localidad y el Equipo PEI de la Subsecretaría Académica. Este procedimiento ha mostrado cómo en su gran mayoría los proyectos presentados no involucran a los estudiantes en su desarrollo, criterio central establecido en la convocatoria. La intencionalidad de las instituciones educativas, ha estado más centrada en la consecusión de recursos materiales para mejorar la infraestructura o el mobiliario, y en otros casos, en la formación de los educadores. Al no tener clara una mirada pedagógica cuesta trabajo definir acciones que se desarrollen con los y las estudiantes, por tal razón resulta 


\section{Santafé}

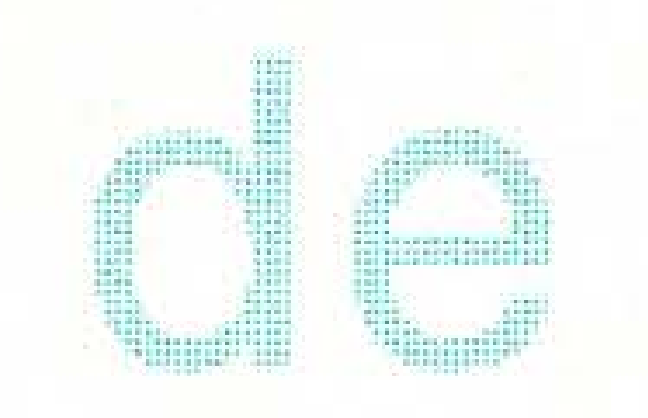

más fácil decidir la compra de un mueble o levantar una pared que presupuestar un seminario de formación o una actividad creativa que va más allá de la acción diaria del salón de clase.

Con el anterior estado de la situación y bajo el criterio fundamental de la Secretaría de Educación de fortalecer y ahondar en los procesos pedagógicos desde una actitud formadora, el Equipo PEI establece como premisa no rechazar los proyectos, dándose a la tarea de discutir su sentido, sus fines y la necesidad de reorientarlos en la perspectiva de la gestión propiamente pedagógica, centrada en la formación de los estudiantes, entendiendo que ello supone un proceso alterno de formación de los maestros.

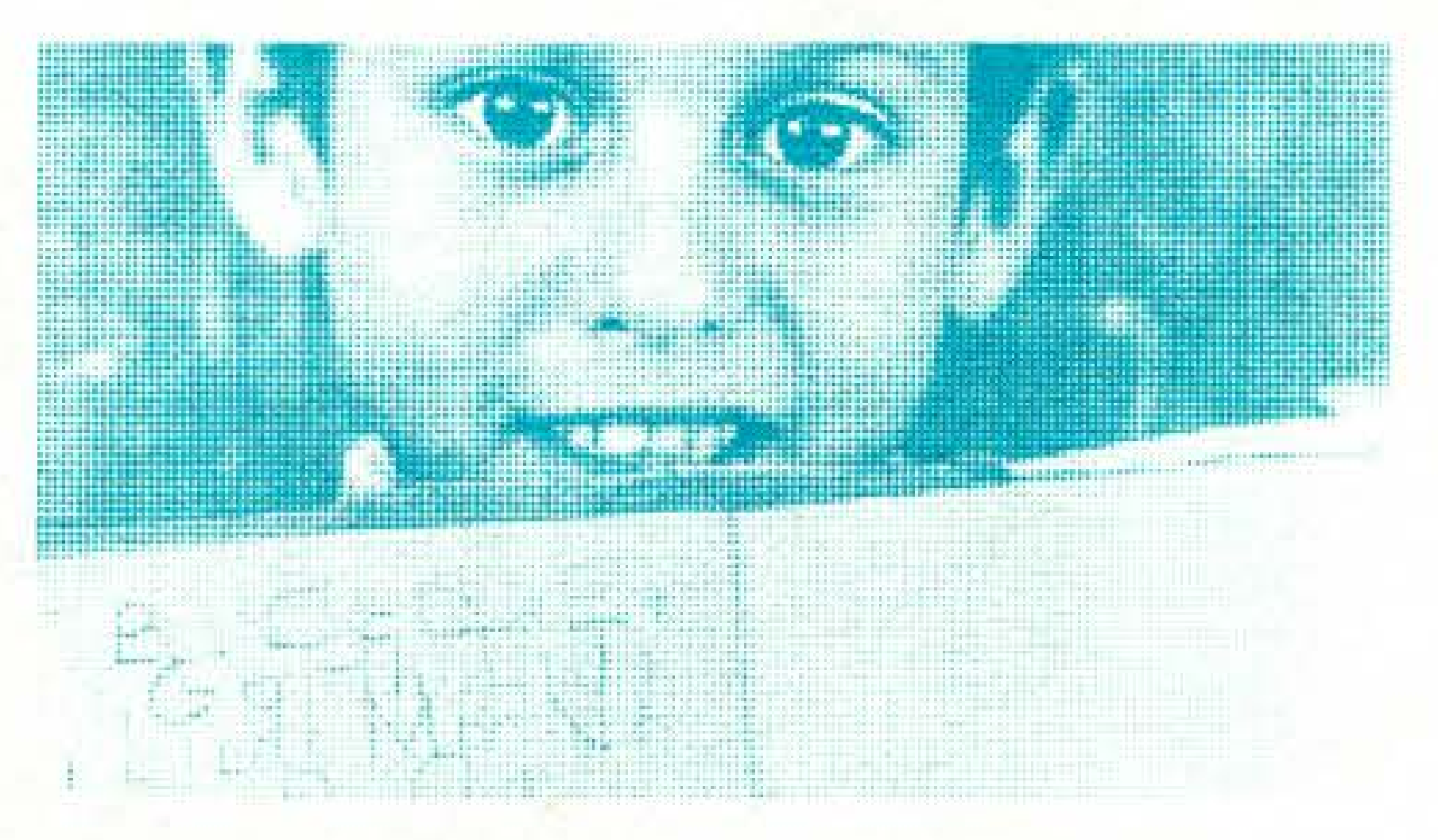

Este ejercicio se convierte en un proceso didáctico que permite asignar recursos para 240 proyectos pedagógicos en el año 1997. En orden de presentación, los proyectos presentados desarrollan propuestas sobre lenguaje y comunicación; convivencia y democracia; medio ambiente; tecnología; ciencias y matemáticas; estética; juego, tiempo libre y lúdica.
Se ha podido establecer, aunque de manera asistemática, que este procedimiento adoptado por la Subsecretaría Académica ha generado entusiasmo y una dinámica fuerte en varias instituciones estatales de la ciudad. Se viene indagando por la nueva convocatoria, con el argumento de que ya se tienen o se están formulando nuevos proyectos. Sostener una acción como ésta o con una intencionalidad similar permi- tiría fortalecer muy específicamente los procesos de gestión administrativa, pedagógica y curricular de las instituciones educativas. 